\title{
ERRATUM
}

\section{Seasonality of birth in children and young adults (0-29 years) with type 1 diabetes in Ukraine}

\author{
A. M. Vaiserman - B. Carstensen - V. P. Voitenko • \\ M. D. Tronko • V. I. Kravchenko • M. D. Khalangot • \\ L. V. Mechova
}

Published online: 16 February 2007

(C) Springer-Verlag 2007

Diabetologia (2007) 50:32-35

Unfortunately, Fig. 1 was printed in black and white instead of in colour. The correct version appears below:

Fig. 1 The layout of the study. Persons in the study are those diagnosed inside the triangular grid and alive at the end of 2003. Persons dying before the end of 2003 are not in the database. Each subset of the grid is further subdivided in 12 subgroups by month of birth for analysis of seasonality. Male: blue, female: red

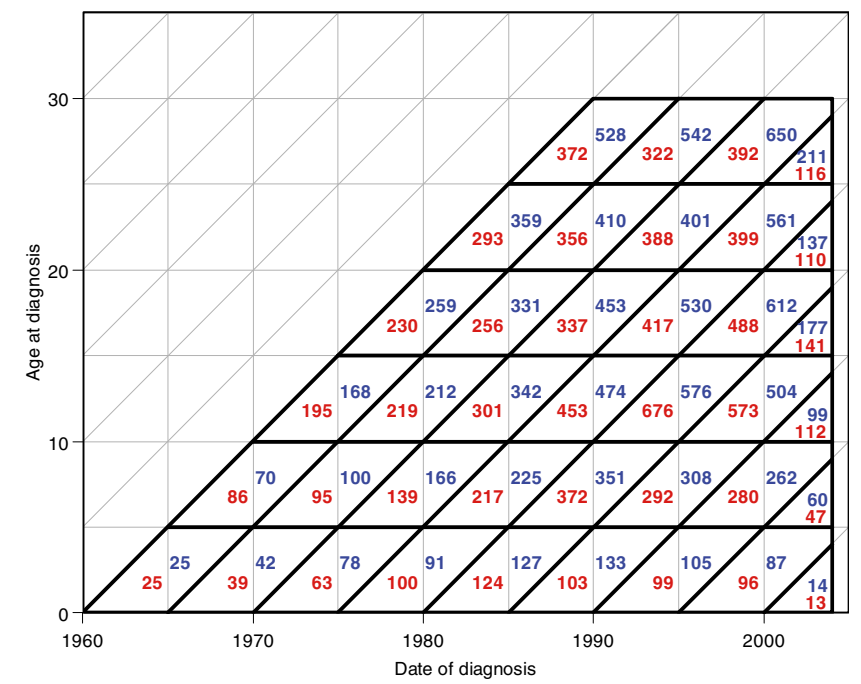

The online version of the original article can be found at: http://dx.doi. org/10.1007/s00125-006-0456-4.

A. M. Vaiserman $(\bowtie) \cdot$ V. P. Voitenko $\cdot$ L. V. Mechova

Laboratory of Mathematical Modelling of Ageing Processes,

Institute of Gerontology,

Vyshgorodskaya st. 67,

Kiev 04114, Ukraine

e-mail: vaiserman@geront.kiev.ua

M. D. Tronko • V. I. Kravchenko • M. D. Khalangot

Department of Epidemiology,

Institute of Endocrinology and Metabolism,

Kiev, Ukraine

B. Carstensen

Steno Diabetes Center,

Gentofte, Denmark 